\title{
Hostility and registered sickness absences: a prospective study of municipal employees
}

\author{
J. VAHTERA, ${ }^{1}$ M. KIVIMÄKI, M. KOSKENVUO AND J. PENTTI \\ From the Turku Regional Institute of Occupational Health; the Finnish Institute of Occupational Health, \\ Department of Psychology, Helsinki; and the Department of Public Health, University of Turku, Finland
}

\begin{abstract}
Background. Prior evidence on the relationship between hostility and minor health problems is limited to cross-sectional self-report studies. In the present study, this relationship was examined prospectively.

Methods. Hostility of 1077 municipal employees was measured by a questionnaire survey and minor health problems by using 4-year register-based absence data including medically certificated diagnoses.

Results. High hostility predicted a high total number of long-term sickness absence spells among men, but not among women. In separate diagnostic categories (musculo-skeletal, traumas and injuries, respiratory), hostility related positively and linearly to absences due to traumatic causes and curvilinearly (U-shape) to absences due to musculo-skeletal causes. Controlling the effects of health risk behaviour and demographic background did not significantly change these figures. However, health risk behaviour moderated the relations of hostility to overall long-term sickness absences, and to traumatic and musculo-skeletal absences, being significantly stronger in high-risk groups. No association was found between hostility and non-certificated short-term absence spells.
\end{abstract}

Conclusions. The results suggest that hostility plays a role in the aetiology of minor health problems.

\section{INTRODUCTION}

There is growing evidence that hostility may contribute to some major health problems and disease endpoints (Smith \& Frohm, 1985; Dembroski et al. 1989). In several prospective studies, hostility has been related to hospitalization and mortality in a variety of causes, at least among men (e.g. Barefoot et al. 1983, 1989; Shekelle et al. 1983; Romanov et al. 1994). Studies on coronary heart disease (CHD) have suggested that hostility, representing a component of the Type A behaviour pattern (TABP), is also an important risk factor in CHD (Barefoot et al. 1983; Koskenvuo et al. 1988). In fact, the association between hostility and CHD has been found even in those studies where the

${ }^{1}$ Address for correspondence: Dr Jussi Vahtera, Turku Regional Institute of Occupational Health, Hämeenkatu 10, FIN-20500 Turku,
Finland. global TABP has not been related to CHD (Koskenvuo et al. 1988; Julkunen et al. 1994).

While the potential impacts of hostility on severe health problems have been extensively studied, the association between hostility and minor health impairments is not very well known. Up to the present, this association has almost exclusively been investigated by questionnaire studies. The findings have consistently suggested that hostile people report more health problems, daily stress and tension (Houston \& Kelly, 1989; Chen \& Spector, 1992; Siegel, 1992). However, a major limitation of these studies is the reliance on cross-sectional selfreports, which makes the results vulnerable to common method-variance biases.

The aim of this study was to investigate prospectively the relation of hostility to health impairments as indicated by sickness absence information. We hypothesized that hostility is 
associated with the number of health problems, at least among men, after the effects of health risk behaviour (i.e. excessive consumption of alcohol, regular smoking, obesity and sedentary life style) and demographics are controlled.

\section{METHOD}

\section{Subjects and procedure}

In 1990, 1110 identifiable full-time municipal employees of the town of Raisio, in southwestern Finland, responded to a questionnaire assessing hostility. The response rate was $95 \%$ of the total municipal personnel in Raisio. Three years after the initial survey (i.e. in 1993), a follow-up was conducted to detect the long-term stability of hostility ratings. Data on the absenteeism of the respondents were gathered for 4 years after the base-line survey. Those employees who had replied to the hostility questions and had been at work for at least 6 months after the survey were included in the study cohort of 1077 persons (261 men and 816 women). The total follow-up time was 956 person years for men and 2786 person years for women.

\section{Measures}

\section{Hostility}

This was measured by a 3-item scale derived from Koskenvuo et al. (1988). The items are selfratings of anger-proneness ('do not get angry easily... get angry easily'), irritability ('get irritated easily... do not get irritated easily'), and argumentativeness ('seldom prone to get into arguments easily ... quite often prone to get into arguments'), tapping particularly the affective and behavioural components of hostility. Responses to the items were given on a 7point Likert-type scale. The construct validity of the scale has proved to be satisfactory (Romanov et al. 1994; Strandberg et al. 1994). The internal consistency and long-term stability of the scale were moderate in our sample (coefficient alpha reliability $0 \cdot 77$, 3-year test-retest reliability $0 \cdot 67$ ).

\section{Registered sick-leave absenteeism}

The data were gathered from the occupational health care unit's register. This computer-based register contains each sick-leave period of every employee in identifiable form, giving the beginning and end dates of each spell, and the code to classify the main diagnosis, made by the occupational health care specialist. Each sickleave certificate, irrespective of the place of issue, must be forwarded to the register. For sickness absences of 1 to 3 days, the employees are allowed to complete their own certificate explaining their absence. All the subjects' sickness absence spells between 1 January 1991 and 31 December 1994 were obtained from the register. The records were checked for inconsistencies. Overlapping, consecutive, or duplicate spells of sickness absence were combined. Sickness absence spells were divided into short and long (over 3 days; medical certificate required) ones, taken all together, and long spells separately for the three most common diagnostic categories (International Classification of Diseases, 1977 Revision, WHO, 1977): musculo-skeletal diseases, traumatic causes, and respiratory diseases.

\section{Annual income}

Information on annual income was obtained from the employer's register where it was grouped into categories 1 to 17 , each succeeding class reflecting an increase of 12000 Finnish marks in annual income.

\section{Health risk behaviour}

Self-report items in the survey included measures of health risk behaviour: regular smoking (yes/no), average consumption of units of beer, wine and spirits in a week (cut-off point for low consumption $40 \mathrm{~g} /$ week and for high consumption $280 \mathrm{~g}$ /week for men, and $180 \mathrm{~g} /$ week for women), weight and height to determine body mass index (BMI), and leisure time physical activity. The survey also included a list of 13 chronic diseases diagnosed by a doctor (e.g. asthma, rheumatoid arthritis, osteoarthritis, sciatica, diabetes, cardiovascular disease) and an open question about chronic diseases not included in the list. Three measures were derived from this information: a disease in general (yes/no), and specifically a musculo-skeletal disease (yes/no) and a respiratory disease (yes/no).

\section{Statistical analyses}

The analyses of the relationship between the hypothesized determinants and absence spells were conducted according to North et al. (1993). For each employee, the number of sickness 
Table 1. Mean hostility scores of potential predictors of sickness absence, standard error of mean $(S E M)$, the significance for the difference (F-value, degrees of freedom $(d f)$ ), and absence rate/100 person years ( $p y)$ for long spells of absence. High hostility gives high scores

\begin{tabular}{|c|c|c|c|c|c|}
\hline & $N$ & $\begin{array}{c}\text { Mean } \\
\text { hostility }\end{array}$ & S.E.M. & $F(\mathrm{df})$ & $\begin{array}{c}\text { Long spells } / 100 \\
\text { person years } \\
\text { age, gender adjusted }\end{array}$ \\
\hline Men & 261 & $8 \cdot 9$ & $0 \cdot 22$ & $1.61(1,1076)$ & $42 \cdot 49$ \\
\hline Women & 816 & $9 \cdot 3$ & $0 \cdot 14$ & & $50 \cdot 86^{* *}$ \\
\hline Age & & & & $2 \cdot 88(2,1076)$ & \\
\hline$\leqslant 33$ & 258 & $9 \cdot 6$ & $0 \cdot 25$ & & $43 \cdot 53$ \\
\hline $34-48$ & 560 & $9 \cdot 2$ & $0 \cdot 16$ & & $50 \cdot 59$ \\
\hline$>48$ & 259 & $8 \cdot 8$ & $0 \cdot 22$ & & $64 \cdot 36^{* * *}$ \\
\hline Income level & & & & $2 \cdot 71(2,1071)$ & \\
\hline High & 382 & $9 \cdot 6$ & $0 \cdot 21$ & & $25 \cdot 15$ \\
\hline Average & 440 & $9 \cdot 1$ & $0 \cdot 18$ & & $45 \cdot 25$ \\
\hline Low & 250 & $8 \cdot 9$ & $0 \cdot 22$ & & $65 \cdot 70^{* * *}$ \\
\hline \multicolumn{6}{|l|}{ Marital status $\dagger$} \\
\hline Men & & & & $2 \cdot 96(1,260)$ & \\
\hline Married & 211 & $9 \cdot 1$ & $0 \cdot 25$ & & $42 \cdot 60$ \\
\hline Single & 50 & $8 \cdot 2$ & $0 \cdot 46$ & & $44 \cdot 86$ \\
\hline Women & & & & $1 \cdot 26(1,815)$ & \\
\hline Married & 646 & $9 \cdot 2$ & $0 \cdot 15$ & & $50 \cdot 23$ \\
\hline Single & 170 & $9 \cdot 6$ & $0 \cdot 31$ & & $52 \cdot 06$ \\
\hline Alcohol consumption & & & & $1.90(2,1056)$ & \\
\hline Low & 507 & $9 \cdot 1$ & $0 \cdot 17$ & & $53 \cdot 50$ \\
\hline Average & 449 & $9 \cdot 0$ & $0 \cdot 17$ & & $47 \cdot 03$ \\
\hline High & 101 & $9 \cdot 8$ & $0 \cdot 42$ & & $50 \cdot 11^{*}$ \\
\hline Smoking & & & & $10 \cdot 77(1,1075)^{* *}$ & \\
\hline No & 866 & $9 \cdot 0$ & $0 \cdot 13$ & & $47 \cdot 12$ \\
\hline Yes & 210 & $10 \cdot 0$ & $0 \cdot 27$ & & $68 \cdot 64 * * *$ \\
\hline Physical activity & & & & $0 \cdot 35(2,1051)$ & \\
\hline Sedentary lifestyle & 85 & $9 \cdot 5$ & $0 \cdot 41$ & & $68 \cdot 85^{* * *}$ \\
\hline Moderate & 897 & $9 \cdot 1$ & $0 \cdot 13$ & & 48.97 \\
\hline Vigorous training & 70 & $9 \cdot 1$ & $0 \cdot 51$ & & $59 \cdot 51$ \\
\hline \multicolumn{6}{|l|}{ Body mass index $\dagger$} \\
\hline Men & & & & $3.61(2,258)^{*}$ & \\
\hline$<23 \mathrm{~kg} / \mathrm{m}^{2}$ & 56 & $7 \cdot 9$ & $0 \cdot 41$ & & $31 \cdot 52$ \\
\hline $23-27 \mathrm{~kg} / \mathrm{m}^{2}$ & 139 & $9 \cdot 2$ & $0 \cdot 31$ & & $42 \cdot 78$ \\
\hline$>27 \mathrm{~kg} / \mathrm{m}^{2}$ & 64 & $9 \cdot 4$ & $0 \cdot 46$ & & $56 \cdot 04 * * *$ \\
\hline Women & & & & $1 \cdot 19(2,807)$ & \\
\hline$<23 \mathrm{~kg} / \mathrm{m}^{2}$ & 381 & $9 \cdot 4$ & $0 \cdot 20$ & & $38 \cdot 65$ \\
\hline $23-27 \mathrm{~kg} / \mathrm{m}^{2}$ & 277 & $9 \cdot 4$ & $0 \cdot 23$ & & $56 \cdot 63$ \\
\hline$>27 \mathrm{~kg} / \mathrm{m}^{2}$ & 150 & $8 \cdot 8$ & $0 \cdot 30$ & & $74 \cdot 20^{* * *}$ \\
\hline Diagnosed disease & & & & $0 \cdot 46(1,1073)$ & \\
\hline No & 491 & $9 \cdot 1$ & $0 \cdot 16$ & & $32 \cdot 41$ \\
\hline Yes & 583 & $9 \cdot 3$ & $0 \cdot 16$ & & $66 \cdot 36 * * *$ \\
\hline Musculo-skeletal disease & & & & $0 \cdot 68(1,1073)$ & \\
\hline No & 807 & $9 \cdot 3$ & $0 \cdot 13$ & & $42 \cdot 74$ \\
\hline Yes & 267 & $9 \cdot 0$ & $0 \cdot 25$ & & $77 \cdot 95^{* * *}$ \\
\hline
\end{tabular}

$\dagger$ Interaction with gender on hostility significant.

absences was computed and the follow-up period was measured in person years. The number of sickness absence spells is a form of count data and therefore Poisson regression models were applied (McCullagh \& Nelder, 1989; SAS, 1993). The assumption for the model is that: $\log$ (number of spells) is log (person years) + $b_{0}+b_{1} x_{1}+\ldots+b_{n} x_{n}$, where $x$ is the predictor and $b$ the coefficient of $x(i=1-n)$. The rate ratios are derived from the equation: $R R_{i}=$ $\operatorname{spells}\left(x_{i}=1\right) / \operatorname{spells}\left(x_{i}=0\right)=e^{b i}$. When the dispersion of sickness absence spells was greater than that predicted by the Poisson model, a scale parameter (the square root of deviance divided by degrees of freedom) was used to adjust for standard errors. 
In the first stage, the associations of demographic variables and health-risk behaviour with hostility, and with absence spells were studied. Interactions with gender were analysed using cross-product term as recommended by Cohen $\&$ Cohen (1983), and for variables with significant gender interactions, analyses were conducted separately for men and women (a procedure also used in the subsequent stages).

In the next stage, the relations of hostility to overall absences and to absences with specified diagnostic categories were studied. The results were expressed as absence rates/100 person years and as rate ratios. Absence rates and their corresponding rate ratios were adjusted for age and gender and for the base-line potential confounders found in the first stage. These were the demographic and health-risk behaviour variables which independently predicted absences in a multivariate regression model. Linearity between hostility and absence spells was studied using the linear term applied in the Poisson models. Curvilinear trend was tested using the cross-product term hostility $\times$ hostility as recommended by Cohen \& Cohen (1983).

In the third stage, the moderated effects of demographic variables and health-risk behaviour on the relationship between hostility and absence spells were studied (Cohen \& Cohen, 1983).

All the analyses were performed with the SAS statistical program package and the Poisson regression models were calculated using the GENMOD procedure (SAS, 1993).

\section{RESULTS}

Three of the studied demographic and health risk behaviour variables were associated with hostility (Table 1). Smokers were more hostile than non-smokers irrespective of gender. In men, high BMI was related to high hostility, whereas in women such an association was not found. For marital status, the association was stronger for men than for women, suggesting that married men reported a higher hostility score than single men.

All the studied demographic and health risk behaviour variables, except marital status, predicted long absence spells (Table 1). For example, smoking and sedentary life-style predicted an over $40 \%$ and high BMI an $80 \%$ increase in absence spells.

Hostility predicted the total number of long absence spells, but only among males (Table 2). Men with a high hostility had $78 \%$ more such spells than men with a low hostility. The linear trend was highly significant. In separate diagnostic categories, hostility predicted absences due to traumas and musculo-skeletal disorders irrespective of gender. The linearly increasing trend showed that the number of long absence spells due to traumatic causes was two times higher in the high hostility group than in the low hostility group. For musculo-skeletal disorders, the relation was U-shaped, the highest rates being among the least and the most hostile employees and those in between having $40 \%$ lower absence rates. This curvilinear trend was highly significant.

Adjustment for all the potential confounders in addition to age and gender (i.e. marital status, income level, alcohol consumption, smoking, sedentary life style, obesity, baseline diagnosed diseases) had only a modest impact on the relationship between hostility and absence (Table 2). Hostility was related neither to absences due to respiratory causes (not shown in the tables) nor to short absence spells (Table 2).

Finally, we studied whether demographic or health risk behaviour variables moderate the relationship between hostility and absence spells. As indicated by the three-way interactions of moderator $\times$ hostility $\times$ gender (Table 3 ), these moderations were in many cases different for males and females, and, therefore, we made the analyses separately for men and women. For demographics, the relationship between hostility and absence due to musculo-skeletal causes was most pronounced when high hostility was associated with low income level (only in women), married marital status (only in men), and absence of musculo-skeletal self-reported diagnosis at the time of baseline measurement (only in men). Age did not moderate the relation between hostility and absence.

The association of hostility with absence spells also depended on health risk behaviour (Table 3). More specifically, the combination of high hostility with high alcohol consumption or sedentary lifestyle (only in men) produced the highest total number of long spells. For absence due to musculo-skeletal causes, the figures were 
Table 2. Sickness absence according to hostility level expressed as absence rates/100 person years $(p y)$, and the rate ratios $(R R)$ relative to the rate in least hostile adjusted partially (age, gender) and fully adjusted. Test for linearity and curvilinearity gives $\chi^{2}$ value and its significance

\begin{tabular}{|c|c|c|c|c|c|c|}
\hline & $N$ & $\begin{array}{l}\text { Absence rate/ } \\
100 \text { py } \\
\text { age, gender } \\
\text { adjusted }\end{array}$ & $\begin{array}{c}\text { RR } \\
\text { age, gender } \\
\text { adjusted }\end{array}$ & $\begin{array}{c}\mathrm{RR} \\
\text { fully } \\
\text { adjusted }\end{array}$ & $\begin{array}{c}\text { Linear } \\
\text { trend } \\
\chi^{2}(\mathrm{df}=1)\end{array}$ & $\begin{array}{c}\text { Curvilinear } \\
\text { trend } \\
\chi^{2}(\mathrm{df}=1)\end{array}$ \\
\hline \multicolumn{7}{|l|}{ Short spells } \\
\hline Hostility & & & & & $7 \cdot 25^{* *}$ & 0.83 \\
\hline $3-5$ & 185 & $79 \cdot 16$ & $1 \cdot 00$ & $1 \cdot 00$ & & \\
\hline $6-7$ & 223 & $76 \cdot 71$ & 0.97 & 0.97 & & \\
\hline $8-9$ & 188 & $79 \cdot 23$ & 1.00 & 1.00 & & \\
\hline $10-12$ & 260 & $93 \cdot 32$ & $1 \cdot 18$ & $1 \cdot 18$ & & \\
\hline $13-21$ & 221 & 93.84 & $1 \cdot 19$ & $1 \cdot 21$ & & \\
\hline \multicolumn{7}{|l|}{ Long spells } \\
\hline Men, hostility & & & & & $12 \cdot 90^{* * *}$ & $7 \cdot 40^{* *}$ \\
\hline $3-5$ & 44 & $32 \cdot 74$ & $1 \cdot 00$ & $1 \cdot 00$ & & \\
\hline $6-7$ & 59 & $39 \cdot 10$ & $1 \cdot 19$ & $1 \cdot 08$ & & \\
\hline $8-9$ & 44 & $49 \cdot 51$ & $1 \cdot 51^{*}$ & 1.39 & & \\
\hline $10-12$ & 66 & 38.58 & $1 \cdot 18$ & 0.87 & & \\
\hline $13-21$ & 48 & $58 \cdot 42$ & $1.78^{* * *}$ & $1 \cdot 41^{*}$ & & \\
\hline Women, hostility & & & & & $2 \cdot 44$ & $6 \cdot 12 *$ \\
\hline $3-5$ & 141 & $53 \cdot 18$ & $1 \cdot 00$ & 1.00 & & \\
\hline $6-7$ & 164 & $47 \cdot 93$ & 0.90 & 0.94 & & \\
\hline $8-9$ & 144 & $43 \cdot 33$ & $0 \cdot 81^{*}$ & 0.90 & & \\
\hline $10-12$ & 194 & $50 \cdot 70$ & 0.95 & $1 \cdot 00$ & & \\
\hline $13-21$ & 173 & $56 \cdot 50$ & 1.06 & 1.06 & & \\
\hline \multicolumn{7}{|c|}{ Musculo-skeletal spells } \\
\hline Hostility & & & & & $0 \cdot 03$ & $13 \cdot 90^{* * *}$ \\
\hline $3-5$ & 185 & $18 \cdot 05$ & $1 \cdot 00$ & $1 \cdot 00$ & & \\
\hline $6-7$ & 223 & $12 \cdot 65$ & $0 \cdot 74 * *$ & $0.73 *$ & & \\
\hline $8-9$ & 188 & $11 \cdot 14$ & $0.62 * * *$ & $0 \cdot 67 * *$ & & \\
\hline $10-12$ & 260 & $12 \cdot 88$ & $0.71^{* *}$ & $0 \cdot 66^{* *}$ & & \\
\hline $13-21$ & 221 & $17 \cdot 57$ & 0.97 & $0 \cdot 89$ & & \\
\hline \multicolumn{7}{|l|}{ Traumatic causes } \\
\hline Hostility & & & & & $9 \cdot 31 * *$ & 0.43 \\
\hline $3-5$ & 185 & $3 \cdot 46$ & $1 \cdot 00$ & $1 \cdot 00$ & & \\
\hline $6-7$ & 223 & $4 \cdot 64$ & $1 \cdot 34$ & $1 \cdot 29$ & & \\
\hline $8-9$ & 188 & $5 \cdot 46$ & 1.58 & $1 \cdot 61$ & & \\
\hline $10-12$ & 260 & $5 \cdot 20$ & $1 \cdot 50$ & $1 \cdot 40$ & & \\
\hline $13-21$ & 221 & $7 \cdot 23$ & $2 \cdot 09^{* *}$ & $1 \cdot 87^{* *}$ & & \\
\hline
\end{tabular}

Note: For long spells gender $\times$ hostility interaction significant.

Fully adjusted models include in addition to gender and age for long spells and musculo-skeletal spells income, smoking, physical activity and BMI; and for traumatic causes gender $\times$ marital status interaction, alcohol consumption, smoking and physical activity.

${ }^{*} P \leqslant 0.05 ; * * P<0.01 ; * * * P<0.001$.

elevated when high hostility was combined with high alcohol consumption, sedentary lifestyle or high BMI (only in men). The combination of high hostility with sedentary lifestyle or regular smoking (only in men) yielded the highest number of absences due to traumatic causes.

\section{DISCUSSION}

In support of our hypothesis, hostility was associated with health problems indicated by absenteeism. The present results suggest, consistently with recent survey studies (Houston \&
Kelly, 1989; Chen \& Spector, 1992; Siegel, 1992), that hostility may contribute to minor health impairments among men and women. These main findings remained constant after the effects of health risk behaviour and demographic background were partialled out.

More detailed analyses showed that the relation of hostility to health problems was dependent on gender and diagnostic category. While the total number of health problems, as indicated by medically certificated absence spells, was predicted by hostility only in men, traumas and injuries were predicted by hostility in both 
Table 3. The moderators of the hostility-sickness absence relation in hierarchical Poisson regression analyses. The age adjusted rate ratios of sickness absence in high versus low hostility (ho) at different levels of moderators, and the improvement of the model when entering the moderator $\times$ hostility and the moderator $\times$ hostility $\times$ gender interaction term $\left(\chi^{2}\right.$ value and in parentheses the degrees of freedom)

\begin{tabular}{|c|c|c|c|c|c|c|c|}
\hline \multirow[b]{2}{*}{ Moderator } & \multirow[b]{2}{*}{$\begin{array}{l}\text { ho } \\
\text { low }\end{array}$} & \multicolumn{2}{|c|}{ Long spells } & \multicolumn{2}{|c|}{ Musculo-skeletal spells } & \multicolumn{2}{|c|}{ Traumatic causes } \\
\hline & & $\begin{array}{l}\text { Men } \\
\text { ho } \\
\text { high }\end{array}$ & $\begin{array}{c}\text { Women } \\
\text { ho } \\
\text { high }\end{array}$ & $\begin{array}{l}\text { Men } \\
\text { ho } \\
\text { high }\end{array}$ & $\begin{array}{c}\text { Women } \\
\text { ho } \\
\text { high }\end{array}$ & $\begin{array}{l}\text { Men } \\
\text { ho } \\
\text { high }\end{array}$ & $\begin{array}{c}\text { Women } \\
\text { ho } \\
\text { high }\end{array}$ \\
\hline \multicolumn{8}{|l|}{ Income level } \\
\hline High & $1 \cdot 00$ & 1.57 & $1 \cdot 42$ & $1 \cdot 51$ & $0 \cdot 47$ & $0 \cdot 51$ & $1 \cdot 64$ \\
\hline Average & $1 \cdot 00$ & $1 \cdot 30$ & $1 \cdot 00$ & 0.74 & 0.71 & $2 \cdot 16$ & $2 \cdot 36$ \\
\hline Low & $1 \cdot 00$ & $1 \cdot 07$ & $1 \cdot 09$ & $0 \cdot 13$ & $1 \cdot 33$ & $1 \cdot 80$ & $1 \cdot 06$ \\
\hline$\times$ ho & & NS & NS & NS & $10 \cdot 2(2)^{* *}$ & NS & NS \\
\hline$\times$ ho $\times$ gender & & \multicolumn{2}{|c|}{ NS } & \multicolumn{2}{|c|}{$6 \cdot 0(2)^{*}$} & \multicolumn{2}{|c|}{ NS } \\
\hline \multicolumn{8}{|l|}{ Marital status } \\
\hline Married & $1 \cdot 00$ & 1.67 & $1 \cdot 15$ & $1 \cdot 33$ & $1 \cdot 19$ & 1.82 & 1.72 \\
\hline Single & $1 \cdot 00$ & $0 \cdot 84$ & 0.91 & $0 \cdot 18$ & $0 \cdot 76$ & 1.55 & 0.97 \\
\hline$\times$ ho & & $4 \cdot 9(1)^{*}$ & NS & $13 \cdot 7(1)^{* * *}$ & NS & NS & NS \\
\hline$\times$ ho $\times$ gender & & \multicolumn{2}{|c|}{ NS } & \multicolumn{2}{|c|}{$6 \cdot 7(1)^{* *}$} & \multicolumn{2}{|c|}{ NS } \\
\hline \multicolumn{8}{|l|}{ Alcohol consumption } \\
\hline Low & $1 \cdot 00$ & $0 \cdot 81$ & $1 \cdot 00$ & $0 \cdot 31$ & $0 \cdot 94$ & $1 \cdot 74$ & $1 \cdot 48$ \\
\hline Average & $1 \cdot 00$ & $1 \cdot 35$ & $1 \cdot 14$ & $0 \cdot 84$ & $1 \cdot 13$ & $1 \cdot 00$ & $1 \cdot 44$ \\
\hline High & 1.00 & $2 \cdot 05$ & $2 \cdot 20$ & $1 \cdot 54$ & $10 \cdot 5$ & $2 \cdot 59$ & $1 \cdot 31$ \\
\hline$\times$ ho & & $8 \cdot 5(2)^{*}$ & $11 \cdot 5(2)^{* *}$ & $6 \cdot 4(2)^{*}$ & $15 \cdot 9(2)^{* * *}$ & NS & NS \\
\hline$\times$ ho $\times$ gender & & \multicolumn{2}{|c|}{ NS } & \multicolumn{2}{|c|}{ NS } & \multicolumn{2}{|c|}{ NS } \\
\hline \multicolumn{8}{|l|}{ Smoking } \\
\hline No & $1 \cdot 00$ & $1 \cdot 26$ & 1.06 & $1 \cdot 03$ & 0.95 & $0 \cdot 88$ & $1 \cdot 45$ \\
\hline Yes & $1 \cdot 00$ & $1 \cdot 76$ & $1 \cdot 05$ & $0 \cdot 62$ & $1 \cdot 33$ & $3 \cdot 84$ & $1 \cdot 18$ \\
\hline$\times$ ho & & NS & NS & NS & NS & $11 \cdot 5(1)^{* * *}$ & NS \\
\hline$\times$ ho $\times$ gender & & \multicolumn{2}{|c|}{ NS } & \multicolumn{2}{|c|}{ NS } & \multicolumn{2}{|c|}{$8 \cdot 7(1)^{* *}$} \\
\hline \multicolumn{8}{|l|}{ Physical activity } \\
\hline Sedentary lifestyle & $1 \cdot 00$ & $3 \cdot 59$ & $1 \cdot 60$ & $3 \cdot 15$ & $2 \cdot 08$ & $4 \cdot 29$ & $1 \cdot 90$ \\
\hline Moderate & $1 \cdot 00$ & $1 \cdot 14$ & $1 \cdot 06$ & $0 \cdot 51$ & $1 \cdot 08$ & $1 \cdot 57$ & $1 \cdot 17$ \\
\hline Vigorous training & $1 \cdot 00$ & 0.98 & $0 \cdot 95$ & $0 \cdot 41$ & $0 \cdot 04$ & $0 \cdot 73$ & $4 \cdot 40$ \\
\hline$\times$ ho & & $18 \cdot 9(2)^{* * *}$ & NS & $16 \cdot 0(2)^{* * *}$ & $28 \cdot 3(2)^{* * *}$ & $6 \cdot 3(1)^{*}$ & $6 \cdot 5(1)^{*}$ \\
\hline$\times$ ho $\times$ gender & & \multicolumn{2}{|c|}{ NS } & \multicolumn{2}{|c|}{$11 \cdot 0(2)^{* * *}$} & \multicolumn{2}{|c|}{$7 \cdot 9(2)^{*}$} \\
\hline Body mass index & & & & & & & \\
\hline$<23 \mathrm{~kg} / \mathrm{m}^{2}$ & $1 \cdot 00$ & 1.06 & $1 \cdot 26$ & $0 \cdot 75$ & $1 \cdot 10$ & $0 \cdot 87$ & $1 \cdot 50$ \\
\hline $23-27 \mathrm{~kg} / \mathrm{m}^{2}$ & 1.00 & $1 \cdot 18$ & 1.09 & $0 \cdot 57$ & $1 \cdot 05$ & 1.52 & $1 \cdot 37$ \\
\hline$>27 \mathrm{~kg} / \mathrm{m}^{2}$ & $1 \cdot 00$ & 1.91 & 0.93 & 1.67 & $1 \cdot 19$ & $2 \cdot 43$ & $1 \cdot 33$ \\
\hline$x$ ho & & NS & NS & $5 \cdot 8(2)^{*}$ & NS & NS & NS \\
\hline$\times$ ho $\times$ gender & & & & & & & \\
\hline Musculo-skeletal dise & & & & & & & \\
\hline No & $1 \cdot 00$ & - & - & $1 \cdot 75$ & $1 \cdot 21$ & - & - \\
\hline Yes & $1 \cdot 00$ & - & - & 0.50 & $1 \cdot 01$ & - & - \\
\hline$\times$ ho & & & & $10 \cdot 3(1)^{* *}$ & NS & & \\
\hline$\times$ ho $\times$ gender & & & & & & & \\
\hline
\end{tabular}

${ }^{*} P \leqslant 0.05 ;{ }^{* *} P<0.01 ; * * * P<0.001$

sexes. As an exception to our expectations, the relationship between hostility and musculoskeletal problems appeared to be U-shaped, with the most problems found among those men and women expressing the lowest and highest levels of hostility.

Recently, a focus of increasing interest has been the processes by which hostility leads to adverse health outcomes. According to one view, a linking mechanism may be accidentprone behaviour. This assumption is based on findings that accidental deaths are more frequent among hostile men (Romanov et al. 1994). It has been concluded that a substantial subgroup of the casualties is caused by accident-prone behaviour, although accidents may sometimes be a 
result of the harmful behaviour of someone else or a hazardous environment. The present results regarding injuries among hostile individuals gave additional support to this hypothesis.

It is also hypothesized that hostile individuals are at greater risk of disease due to poor health habits (e.g. poor self-care, regular smoking, over-weight, sedentary life-style, and heavy alcohol consumption, Koskenvuo et al. 1988; Leiker \& Hailey, 1988; Scherwitz et al. 1992; Siegler et al. 1992). The present findings were not consistent with this mediating role of poor health habits. However, strong support was found for their moderating role. It emerged that especially the combination of high hostility and poor health habits proved to be a risk factor for increased health problems and injuries. Moreover, important gender differences emerged. For example, high hostility was associated with high body mass index among men but not among women, corresponding with the findings by Scherwitz et al. (1992). In addition, our findings indicate that the interaction between hostility and body mass index may explain the number of health problems only in men. However, complementary evidence for this finding is largely lacking because much of the prior research on hostility and health has been done with all-male or largely male samples (Smith, 1992).

Hostility may also contribute to health problems through increased psychosocial vulnerability via high levels of interpersonal conflict and negative life-events, and low levels of social support (Darley \& Fazio, 1980; Williams et al. 1980; Smith \& Frohm, 1985; Smith et al. 1988; Appelberg et al. 1991). In our study, musculoskeletal problems accumulated more in hostile married men than in hostile single men. This may reflect the health impact of marital distress and conflicts which have been found to be associated with high hostility in men (Smith et al. 1988). Another observation supporting the vulnerability hypothesis was that high hostility in women increased the adverse impact of low socio-economic status on health. Some important factors related to psychosocial vulnerability, e.g. job control, job demands, social support, social conflicts and control beliefs (Cohen \& Syme, 1985; Duck, 1990; Karasek \& Theorell, 1990; Appelberg et al. 1991; Cox, 1991), were measured but not reported in the present study.
We will focus on this issue more extensively in a forthcoming paper.

\section{Methodological considerations}

In the present study, hostility was measured by the simplest major hostility questionnaire used in this research area. A replication, using other hostility questionnaires, e.g. the Cook-Medley Ho Scale (Cook \& Medley, 1954), or the complementary use of, for example, the Hostility Facet Scoring System (Dembroski et al. 1989), may provide a more comprehensive measurement strategy. Hostility may also share variance with other individual difference variables such as anxiety and depression (Smith \& Frohm, 1985). Thus, it is possible that these variables are partially responsible for the association between hostility and health.

Absence from work is a multicausal phenomenon (Marmot et al. 1993; Nicholson, 1993; North et al. 1993) and the validity of absenteeism as an indicator of health status may be limited especially when short-term uncertificated absences or self-reported absences are concerned. Thus, the lack of association between hostility and health as indicated by short-term absences may be due to validity problems in the health measure.

In contrast to short-term absence, which is more often voluntary, long-term sickness absences appear to reflect quite accurately the health of employees (Marmot et al. 1995). In the present study, the reason for every long absence spell was verified by a physician's medical examination, thus increasing the validity of measurement and minimizing the confounding effects of voluntary absenteeism. Traumatic causes of absence are, by their very nature, particularly objective indicators of an outcome. The fact that hostility predicted injuries even after controlling for potential confounders, e.g. higher exposure to accidents among workers with low socio-economic status or poor health habits, gave additional support to the reliability of the findings.

It should be noted that the present data were more objective than the self-reports which have frequently been used to indicate health problems of hostile individuals in previous studies (Houston \& Kelly, 1989; Chen \& Spector, 1992; Siegel, 1992). In addition, by using register- 
based data, our investigation was not open to common method-variance problems, unlike studies assessing both hostility and health problems by self-reports. Finally, the present absence data reflected minor health problems, information which is not available from the often used morbidity and mortality registers.

\section{Conclusion}

This longitudinal study demonstrated the important role of hostility in contributing to health problems both in men and women. Moreover, it showed that the health risk associated with hostility may vary by health outcome, gender, health habits and socio-demographics. The present findings also gave information about potential processes by which hostility may lead to health impairments.

It is evident that continued research on hostility and health problems is needed before any firm conclusions can be drawn. A better understanding of this issue is not only important in terms of promoting health but also because of the substantial costs of sickness absence to employers and society as a whole. If an intervention (e.g. Shaphiro et al. 1991) is capable of lowering hostility from the highest level to the second highest level in the present data, the estimated reduction in the total number of long absence spells would be $7.9 \%$ in men. When specified into two major areas of health problems in the working population, the reductions in absences would vary between $6.7 \%$ (musculoskeletal disorders) and $8.0 \%$ (traumas) in both sexes.

\section{REFERENCES}

Appelberg, K., Romanov, K., Honkasalo, M.-L. \& Koskenvuo, M. (1991). Interpersonal conflicts at work and psychosocial characteristics of employees. Social Science and Medicine 32, 1051-1056.

Barefoot, J. C., Dahlström, W. G. \& Williams, R. B. Jr (1983). Hostility, CHD incidence, and total mortality: a 25-year follow-up study of 255 physicians. Psychosomatic Medicine 45, 59-63.

Barefoot, J. C., Dodge, K. A., Peterson, B. L., Dahlström, W. G. \& Williams, R. B. Jr (1989). The Cook-Medley Hostility scale: item content and ability to predict survival. Psychosomatic Medicine 51, 46-57.

Chen, P. Y. \& Spector, P. E. (1992). Relationships of work stressors with aggression, withdrawal, theft and substance use: an exploratory study. Journal of Occupational and Organizational Psychology 65, 177-184.

Cohen, J. \& Cohen, P. (1983). Applied Multiple Regression/ Correlation Analysis for the Behavioral Sciences, 2nd edn. Erlbaum: Hillsdale, NJ.
Cohen, S. \& Syme, L. S. (1985). Social Support and Health. Academic Press: New York.

Cook, W. W. \& Medley, D. M. (1954). Proposed hostility and pharisaic-virtue scales for the MMPI. Journal of Applied Psychology 38, 414-418.

Cox, T. (1991). Individual differences, stress and coping. In Personality and Stress: Individual Differences in the Stress Process (ed. C. L. Cooper and R. Payne), pp. 7-30. Wiley: Chichester.

Darley, J. M. \& Fazio, R. H. (1980). Expectancy confirmation processes arising in the social interaction sequence. American Psychologist 35, 867-881.

Dembroski, T. M., MacDougall, J. M., Costa, P. T. Jr \& Grandits, G. A. (1989). Components of hostility as predictors of sudden death and myocardial infraction in the Multiple Risk Factor Intervention Trial. Psychosomatic Medicine 51, 514-522.

Duck, S. (ed.) (1990). Personal Relationships and Social Support. Sage Publications: London.

Houston, B. K. \& Kelly, K. E. (1989). Hostility in employed women: relation to work and marital experiences, social support, stress, and anger expression. Personality and Social Psychology Bulletin 15, 175-182.

Julkunen, J., Salonen, R., Kaplan, G. A., Chesney, M. A. \& Salonen, J. T. (1994). Hostility and the progression of carotid atherosclerosis. Psychosomatic Medicine 56, 519-525.

Karasek, R. \& Theorell, T. (1990). Healthy Work. Stress, Productivity, and the Reconstruction of Working Life. Basic Books: New York.

Koskenvuo, M., Kaprio, J., Rose, R. J., Kesäniemi, A., Sarna, S., Heikkilä, K. \& Langinvainio, H. (1988). Hostility as a risk factor for mortality and ischemic heart disease in men. Psychosomatic Medicine 50, 330-340.

Leiker, M. \& Hailey, B. J. (1988). A link between hostility and disease: poor health habits? Behavioral Medicine 3, 129-133.

McCullagh, P. \& Nelder, J. A. (1989). Generalized Linear Models. Chapman and Hall: London.

Marmot, M. G., North, F., Feeney, A. \& Head, J. (1993). Alcohol consumption and sickness absence: from the Whitehall II study. Addiction 88, 369-382.

Marmot, M. G., Feeney, A., Shipley, M., North, F. \& Syme, S. L. (1995). Sickness absence as a measure of health status and functioning: from the UK Whitehall II study. Journal of Epidemiology and Community Health 49, 124-130.

Nicholson, N. (1993): Absence - there and back again. Journal of Organizational Behavior 14, 288-290.

North, F., Syme, S. L., Feeney, A., Head, J., Shipley, M. J. \& Marmot, M. G. (1993). Explaining socio-economic differences in sickness absence: the Whitehall II study. British Medical Journal 306, 361-366.

Romanov, K., Hatakka, M., Keskinen, E., Laaksonen, H., Kaprio, J., Rose, R. J. \& Koskenvuo, M. (1994). Self-reported hostility and suicidal acts, accidents, and accidental deaths: a prospective study of 21,433 adults aged 25 to 59. Psychosomatic Medicine 56, 328-336.

SAS Institute, Inc. (1993). SAS Technical Report P-243, SAS/STAT Software: The GENMOD Procedure, Release 6.09. SAS Institute, Inc.: Cary, NC.

Scherwitz, L. W., Perkins, L. L., Chesney, M. A., Hughes, G. H., Sidney, S. \& Manolio T. A. (1992). Hostility and health behaviors in young adults: the Cardia study. American Journal of Epidemiology 136, 136-145.

Shaphiro, D. H. Jr, Friedman, M. \& Piaget, G. (1991). Changes in mode of control and self-control for post myocardial infarction patients evidencing Type A behavior: the effects of a cognitive/ behavioral intervention and/or cardiac counselling. International Journal of Psychosomatics 38, 4-12.

Shekelle, R. B., Gale, M., Ostfeld, A. M. \& Paul, O. (1983). Hostility, risk of coronary heart disease, and mortality. Psychosomatic Medicine 45, 109-114.

Siegel, J. M. (1992). Anger and cardiovascular health. In Hostility, Coping, and Health (ed. H. S. Friedman), pp. 49-64. BraunBrumfield: Ann Arbor. 
Siegler, I. C., Peterson, P. L., Barefoot, J. C. \& Williams, R. B. (1992). Hostility during late adolescence predicts coronary risk factors at mid-life. American Journal of Epidemiology 136, 146-154.

Smith, T. W. (1992). Hostility and health: current status of the psychosomatic hypothesis. Health Psychology 11, 139-150.

Smith, T. W. \& Frohm, K. D. (1985). What's so unhealthy about hostility? Construct validity and psycho-social correlates of the Cook and Medley Ho scale. Health Psychology 4, 503-520.

Smith, T. W., Pope, M. K., Sanders, J. D., Allred, K. D. \& O'Keeffe,

J. L. (1988). Cynical hostility at home and work: psychosocial vulnerability across domains. Journal of Research in Personality 22, 525-548

Strandberg, T. E., Räikkönen, K., Partinen, M., Pihl, S., Vanhanen,
H. \& Miettinen, T. A. (1994). Associations of cholesterol lowering by statins with anger and hostility in hypercholesterolemic men. Biological Psychiatry 35, 575-577.

Williams, R. B. Jr, Haney, T. L., Lee, K. L., Kong, Y., Blumenthal, J. A. \& Whalen, R. E. (1980). Type A behavior, hostility, and coronary atherosclerosis. Psychosomatic Medicine 42, 539-549.

Williams, R. B. Jr, Barefoot, J. C. \& Shekelle, R. B. (1985). The health consequences of hostility. In Anger, Hostility, and Behavioral Medicine (ed. M. A. Chesney, S. E. Goldston and R. H. Rosenman), pp. 173-186. Hemisphere: New York.

World Health Organization (1977). WHO Manual of the International Statistical Classification of Diseases, Injuries and Causes of Death, Ninth Revision. WHO: Geneva. 